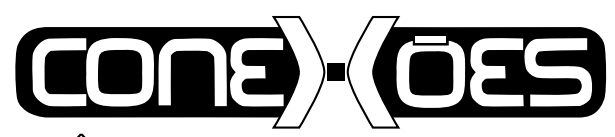

CIÊNCIA E TECNOLOGIA

\title{
A IMPORTÂNCIA DA EXCELÊNCIA NO ATENDIMENTO COMO DIFERENCIAL COMPETITIVO PARA A EMPRESA HOTELEIRA: ESTUDO DE CASO EM UMA POUSADA EM CANOA QUEBRADA - ARACATI/CE
}

\author{
MÔNICA DE SOUSA VIEGAS NUNES ${ }^{1}$, ANGÉLICA DE OLIVEIRA RIBEIRO ${ }^{1}$ \\ ${ }^{1}$ Instituto Federal de Educação, Ciência e Tecnologia do Ceará (IFCE) - Campus Aracati \\ <monica.viegas@ifce.edu.br>,<angel-canoa@hotmail.com>
}

DOI: 10.21439/conexoes.v13i3.1191

\begin{abstract}
Resumo. Pretende-se demonstrar neste artigo a importância da qualidade dos serviços para uma empresa hoteleira manter-se competitiva, pois a qualidade é o fator de sobrevivência nos meios de hospedagem. Além disso, devem ser adotadas ações pela empresa hoteleira a fim de garantir uma qualidade dos serviços, uma vez que a qualidade dos serviços influencia na fidelização dos clientes. Essa pesquisa foi aplicada na Pousada Via Láctea - Canoa Quebrada - Aracati/CE, e teve como objetivo geral identificar o grau de satisfação dos clientes quanto à qualidade dos serviços oferecidos na empresa hoteleira, e como objetivos específicos verificar como os clientes são tratados pelos funcionários no empreendimento hoteleiro; verificar os pontos negativos e positivos quanto à qualidade dos serviços de acordo com a perspectiva dos clientes; propor ações que venham a melhorar a qualidade dos serviços aos clientes e identificar as principais dificuldades em manter a qualidade dos serviços. Em relação à metodologia aplicada, trata-se de um estudo exploratório descritivo, com a utilização de pesquisa de campo. Com a realização da pesquisa concluiu-se que o resultado da análise dos dados coletados foi satisfatório, o que mostra que a Pousada Via Láctea possui qualidade nos serviços prestados, o que torna um diferencial competitivo frente aos outros empreendimentos hoteleiros. E, além disso, constatou-se que os hóspedes são clientes novos que precisam ser fidelizados. Portanto, uma empresa hoteleira deve ser capaz de satisfazer as necessidades dos clientes e superar as suas expectativas, conquistando assim sua fidelização.
\end{abstract}

Palavras-chaves: Atendimento. Fidelização. Qualidade. Satisfação do cliente.

\section{THE IMPORTANCE OF EXCELLENCE IN THE SERVICE AS A COMPETITIVE DIFFERENTIAL FOR THE HOTEL COMPANY: A CASE STUDY IN A INN IN CANOA QUEBRADA - ARACATI/CE}

\begin{abstract}
This paper intends to show the importance of quality service in a hotel in order to be competitive in the market. Therefore, the quality is a survival factor for hospitality facilities. The methodology of the adopted research consisted of an exploratory and descriptive study with a field research. In this research, it was concluded that the result of collecting data was satisfactory. It shows that Via Láctea Inn has a quality service in its services, which makes it a competitive differential against the others hospitality facilities. In addition, it was found that quality service has an impact on customer loyalty. The research was applied to Via Láctea Inn- Canoa Quebrada - Aracati /CE, and it aimed to identify the degree of customer satisfaction regarding the quality service offered by the analyzed lodging facility. As for the specific objectives, it aimed to verify how the staff of the lodging facility approach customers; check the negative and positive points about the service quality according to customer perception; propose actions that will improve the quality of customer service and catalog the main difficulties in keeping the service quality. Besides that, it was concluded that as new guests are new customers, the customer loyalty should be pursued. Therefore, a lodging facility must be able to satisfy customer needs and provide their expectations, in order to achieve their loyalty.
\end{abstract}

Keywords: Service. Loyalty. Quality. Customer satisfaction.

\section{INTRODUÇÃO}

O presente artigo tem por finalidade analisar a qualidade dos serviços prestados na Pousada Via Láctea, lo- calizada em Canoa Quebrada na Rua Descida da Praia, $\mathrm{S} / \mathrm{N}$, no município de Aracati, estado do Ceará. Qualidade é algo que deve estar presente em toda empresa, 
A IMPORTÂNCIA DA EXCELÊNCIA NO ATENDIMENTO COMO DIFERENCIAL COMPETITIVO PARA A EMPRESA HOTELEIRA: ESTUDO DE CASO EM UMA POUSADA EM CANOA QUEBRADA - ARACATI/CE

seja qual for a sua área de atuação, portanto representa um papel importante em todo o ambiente organizacional. Dessa forma, as empresas hoteleiras têm buscado oferecer excelência na qualidade ao atendimento ao cliente, apresentando um diferencial diante de um cenário competitivo no qual muitas empresas oferecem o mesmo tipo de serviço.

A relevância do tema está no fato de que hoje em dia os clientes buscam adquirir bens e serviços que os façam sentir únicos, portanto, a busca por serviços de qualidade é um fator decisivo quando da escolha de produtos de bens e serviços. Dessa forma, quando um empreendimento hoteleiro oferece serviços de qualidade, o cliente fica sempre satisfeito, estabelece-se então uma relação de confiança, consequentemente aquele cliente é fidelizado.

Nesta perspectiva, a pesquisa realizada teve como objetivo geral identificar o grau de satisfação dos clientes quanto à qualidade dos serviços oferecidos no empreendimento hoteleiro. Os objetivos específicos foram a verificação de como os clientes são tratados pelos funcionários no empreendimento hoteleiro; a verificação dos pontos negativos e positivos quanto à qualidade dos serviços de acordo com a perspectiva dos clientes; a proposição de ações que venham a melhorar a qualidade dos serviços aos clientes bem como a identificação das principais dificuldades para manter o status da qualidade dos serviços.

Ademais, pretendeu-se resolver a seguinte problemática: que ações devem ser adotadas pela empresa hoteleira a fim de garantir qualidade dos serviços, uma vez que a qualidade dos serviços impacta na fidelização dos clientes.

Este estudo baseou-se na seguinte hipótese: a insuficiência de qualificação profissional dos funcionários dificulta a fidelização de novos clientes.

Para o desenvolvimento do artigo foi realizado um levantamento de material bibliográfico com o intuito de se investigar sobre a qualidade dos serviços e foram usados dois instrumentos de pesquisa: foi aplicado um roteiro de entrevista com a gerente do empreendimento contendo 14 perguntas abertas. Posteriormente, foi aplicado um questionário dirigido aos hóspedes com 10 perguntas, sendo 9 fechadas e 1 aberta, totalizando 25 questionários que foram aplicados aos hóspedes mediante abordagem, nos dias 16 e 23 de julho de 2016 em alta temporada. Foi considerada a ocupação total da pousada, já que a mesma é de pequeno porte.

Quanto aos objetivos, trata-se de uma pesquisa exploratória e descritiva, sustentada por uma abordagem quantitativa, pois traduzem em números as opiniões e informações coletadas mediante entrevista e aplicação de questionário, para posteriormente chegar a uma conclusão, e qualitativa, já que foi realizada uma análise das respostas dos hóspedes, para compreender a percepção dos mesmos sobre a qualidade dos serviços da Pousada. Os outros dados foram obtidos através de consultas em livros, como também em artigos científicos.

A escolha do empreendimento foi devido à localização estratégica em Canoa Quebrada, a poucos metros da praia, o que a torna um diferencial frente aos concorrentes. Dessa forma, a pousada atrai clientes que procuram um meio de hospedagem perto da praia para usufruir de uma bela vista para o mar e para as falésias. Ademais, o seu fácil acesso também é outro atrativo importante, o hóspede não precisa caminhar muito até chegar a praia, sendo assim, o empreendimento atenderá as necessidades e expectativas dos hóspedes, que é se hospedar em um lugar aconchegante e com uma vista deslumbrante.

\section{CONSIDERAÇÕES TEÓRICAS SOBRE QUALIDADE}

\subsection{Conceitos de Qualidade}

Qualidade é uma palavra chave para todas as empresas de qualquer porte. De acordo com Carvalho e Paladini (2012), apud Custodio (2015, p.14), "Qualidade é a habilidade de um conjunto de características de um produto, processo ou sistema em atender aos requisitos dos clientes e de qualquer outra parte interessada".

Outro conceito é o de Campos (2004, p.2), apud Bond, Busse e Pustilnick (2012, p.13) que diz: "Um produto de qualidade é aquele que atende perfeitamente, de forma confiável, de forma acessível, de forma segura e no tempo certo as necessidades do cliente".

Para Gozzi (2015, p.41), "A qualidade está associada à percepção de excelência nos serviços e produtos, razão pela qual é necessária uma gestão base em dados que possam ser analisados e ajudem a solucionar os problemas existentes.". Já Thurston (1985) apud Bulgacov (2006, p.117) conceitua qualidade deixando clara a necessidade da opinião do cliente quando afirma que "qualidade é aquilo que o cliente percebe quando sente que o produto atende às suas necessidades e satisfaz suas expectativas".

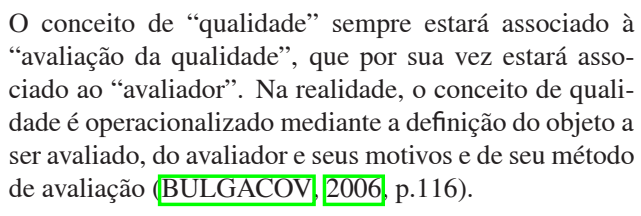

A partir desses conceitos, pode-se afirmar que existem várias definições para qualidade, ou seja, possui um 
A IMPORTÂNCIA DA EXCELÊNCIA NO ATENDIMENTO COMO DIFERENCIAL COMPETITIVO PARA A EMPRESA HOTELEIRA: ESTUDO DE CASO EM UMA POUSADA EM CANOA QUEBRADA - ARACATI/CE

significado muito amplo que está diretamente ligada a percepção de cada cliente, onde muitos irão avaliar de diversas maneiras como, por exemplo, pela aparência do local, pelo preço, etc. Portanto, cada cliente terá sua maneira de interpretar o serviço prestado pelo empreendimento.

\subsection{A Contextualização da Qualidade no Atendi- mento ao Cliente}

A excelência no atendimento é um dos fatores primordiais para alcançar competitividade no mercado. Seja qual for o tamanho do empreendimento hoteleiro, o atendimento ao cliente sempre será o principal diferencial competitivo. O empreendimento pode ser bem sucedido com os clientes através do fornecimento de serviços de qualidade, ou seja, o atendimento ao cliente deve ter prioridade.

\begin{abstract}
A dimensão de "atendimento" é fundamental. Afinal, não são as paredes, os móveis ou a decoração do hotel que vão atender o hóspede, mas a equipe que opera o hotel, é dela que vem a qualidade do atendimento. Fatores como atenção, disponibilidade, atitude cortês, compromisso, simpatia e outros fatores são elementos subjetivos perceptíveis pelo cliente (PETROCCHI 2007 p.25).
\end{abstract}

Como o autor bem coloca, para que haja qualidade no atendimento tem que haver compromisso de toda a equipe, pois o fator humano é muito importante para a construção de um ambiente hospitaleiro. E para atingir essa qualidade, todos os setores da empresa precisam focar no cliente, pois existem muitas empresas de serviços que consideram somente seu ponto de vista e esquecem qual o verdadeiro fim da organização que é atender bem o cliente (PETROCCHI, 2007, p.25).

A qualidade de uma empresa é avaliada pelos seus clientes e concorrentes a todo o momento. Quando uma empresa não atende o cliente com qualidade, pode ocorrer que o concorrente perceba, e como consequência, consegue atrair esse cliente. Para Deming (2003) apud Petrocchil (2007, p.25) é necessário que se tenha foco no cliente e verifique a avaliação feita pelos clientes sobre os serviços que foram prestados, acompanhando as novas tendências e os avanços tecnológicos do mercado.

O hóspede durante sua hospedagem estará sempre avaliando e elaborando um relatório de acordo com sua percepção a respeito dos serviços que lhes são oferecidos, e o resultado disso é extremamente decisivo para a economia da empresa hoteleira. O hóspede ao chegar ao meio de hospedagem estará avaliando o prédio, sua fachada, sua entrada, a decoração e o tratamento que recebe dos funcionários. E enquanto permanecer no estabelecimento o hóspede estará observando cada deta- lhe, para depois fazer seu próprio julgamento e essa impressão será decisiva para a sobrevivência da empresa hoteleira (PETROCCHI, 2007, p.3).

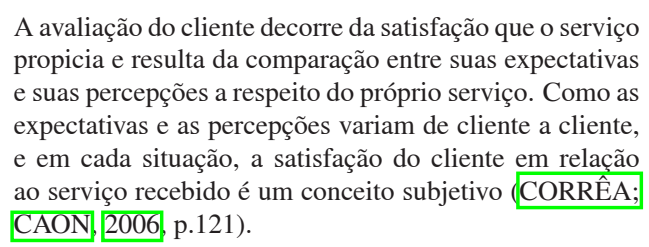

O funcionário deve ser capaz de desenvolver sensibilidade para se apresentar ao cliente adequadamente, pois o cliente usará a aparência do funcionário como um dos elementos para julgar a percepção sobre o serviço que está sendo prestado, para no final julgar o seu nível de satisfação (CORRÊA; CAON, 2006, p.230).

Para Dias e Pimenta (2005, p.90), a qualidade no atendimento envolve vários componentes básicos e indispensáveis como: a aparência, apresentação do funcionário, higiene corporal, cuidado com a indumentária, tom de voz agradável, dicção correta, como também a abordagem feita pelo funcionário que está diretamente relacionada à apresentação.

Diante disso, percebe-se que o prestador de serviço necessita ter aspectos relacionados à formação profissional como o conhecimento, as competências e habilidades para a realização dos serviços.

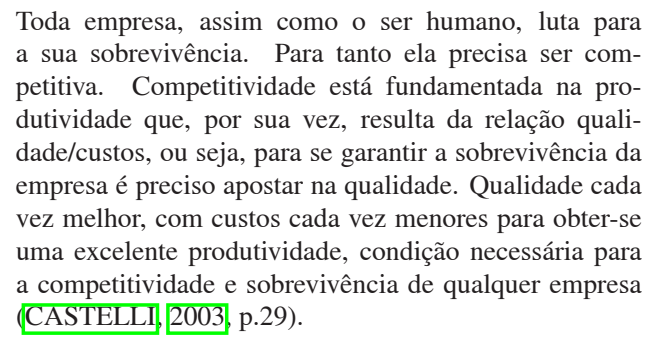

Dessa forma, para que uma empresa se mantenha competitiva no mercado, é importante que ela invista em qualidade. Assim a empresa pode se diferenciar das outras empresas. E essa qualidade depende da estrutura da empresa e também do desempenho de cada funcionário que tem que cumprir o seu papel para o sucesso do estabelecimento. Para Castelli (2003, p.120), uma empresa irá obter sucesso quando produzir aquilo que o cliente deseja, mas para isso, a empresa precisa conhecer o cliente, ou seja, conhecer suas necessidades, seus desejos, comportamentos, suas expectativas, tendências e sua percepção.

\footnotetext{
A partir da implantação de um sistema de qualidade, as pessoas incorporam à sua maneira de trabalhar a necessidade de planejar, definir objetivos e estratégias, avaliar
} 
A IMPORTÂNCIA DA EXCELÊNCIA NO ATENDIMENTO COMO DIFERENCIAL COMPETITIVO PARA A EMPRESA HOTELEIRA: ESTUDO DE CASO EM UMA POUSADA EM CANOA QUEBRADA - ARACATI/CE

resultados, tornando-se mais preparadas para o enfrentamento de quaisquer desafios que a concorrência possa trazer (DIAS; PIMENTA, 2005, p.84).

A implantação de um sistema de qualidade é uma vantagem competitiva frente aos concorrentes para que a empresa consiga manter-se no mercado e ter uma posição de destaque. Uma vez que esse sistema terá como foco a qualidade, e terá como consequência a satisfação e fidelização do cliente. Além disso, quando se implanta um sistema de qualidade, automaticamente se aprimora os serviços que é bastante importante para um empreendimento hoteleiro, afinal, se não há qualidade, consequentemente, irá proporcionar ao cliente uma péssima impressão do local, levando o cliente a não retornar ao empreendimento por causa da falta de qualidade.

\subsection{A Satisfação do Cliente como Diferencial Com- petitivo}

A empresa hoteleira para atingir a satisfação do cliente, deve ser capaz de atender sua necessidade e expectativa, através de serviços de qualidade que proporcionalmente fidelizarão o cliente, fazendo com que retorne outras vezes ao seu empreendimento hoteleiro. Sendo assim terá mais produtividade, e como resultado a lucratividade. Assim, quando os serviços não atendem aos requisitos desejados pelos clientes, torna-se inevitável a mudança para o concorrente, que possivelmente cobrará o mesmo por um serviço superior.

\section{Satisfazer as pessoas significa atender as suas neces- sidades, as necessidades de todas as pessoas com as quais a empresa tem necessariamente compromisso, tais como: empregados, clientes, acionistas e vizinhos (co- munidade). Para tanto é preciso manter um "diálogo" permanente com elas para evitar o desequilíbrio, um sé- rio entrave para a competitividade e sobrevivência da em- presa (CASTELLI, 2003, p.77).}

Para se alcançar a qualidade e manter o cliente satisfeito na prestação dos serviços, o empreendimento hoteleiro deve ser capaz de mudar as formas como gerencia a empresa. Essa mudança e consequente adaptação a novas formas de gerenciar é um elemento necessário para se obter sucesso no empreendimento. Já o prestador de serviço deve ser capaz de ajustar-se às mudanças e atender bem aquilo que o cliente necessita. Para Corrêa e Caon (2006, p.93), "o grau de satisfação do cliente, portanto, por estar diretamente ligado à fidelidade e retenção, e, por conseguinte à lucratividade da organização, tem papel essencial na gestão de serviços".

A gestão da qualidade dos serviços quando feita de forma correta gera níveis de satisfação que irão garantir que o cliente fique fidelizado, pois um cliente fiel será um cliente frequente, que além de voltar, fará o marketing da empresa, fazendo propaganda boca a boca, como também divulgando sua satisfação para as pessoas, e assim, auxiliando para a conquista de novos clientes (CORRÊA; CAON, 2006, p.87).

\footnotetext{
O atendimento deve ser visto como essencial para a satisfação do cliente. É por meio dele que recepcionistas, camareiras, mensageiros, garçons, maîtres podem entender os desejos e as necessidades do hóspede e procurar atendê-los, demonstrando a importância dada a ele e à sua satisfação (DIAS; PIMENTA, 2005, p.90).
}

No mercado competitivo da hotelaria o cliente está cada vez mais exigente com relação à qualidade dos serviços que irá usufruir, ou seja, a qualidade torna-se o diferencial dos serviços oferecidos pela empresa hoteleira. É através do atendimento prestado pelos profissionais envolvidos no empreendimento hoteleiro, que o cliente poderá se sentir satisfeito ou não. Por isso, devese investir na qualidade do atendimento, que tem como objetivo atender de forma correta os clientes, satisfazendo suas necessidades e expectativas.

Os autores Bond, Busse e Pustilnick (2012, p.2829) destacam algumas vantagens de se trabalhar com qualidade:

- Os seus clientes ficam mais satisfeitos com o serviço que recebem, e com isso, confiam em você e voltam a solicitar seus préstimos.

- Você consegue envolver maior número de pessoas que desejam receber seus serviços.

- Você se transforma em um profissional de valor no mercado, tornando-se mais competitivo. O mercado torna-se mais atrativo para você, pois seu trabalho pode ser oferecido a outras organizações ou a outros projetos de trabalho, oportunizando seu crescimento profissional.

- Quando se faz algo com qualidade, os custos são menores, pois você não terá de refazê-lo, por isso, não haverá retrabalho.

- Quando seu trabalho está bem organizado e conquista um nível de qualidade satisfatório, sua produtividade aumenta, pois você tem mais tempo.

\subsection{A Qualificação dos Funcionários do Empreen- dimento Hoteleiro}

O treinamento é importante para que todos os funcionários do empreendimento hoteleiro estejam comprometidos com o trabalho e possam contribuir para a qua- 
A IMPORTÂNCIA DA EXCELÊNCIA NO ATENDIMENTO COMO DIFERENCIAL COMPETITIVO PARA A EMPRESA HOTELEIRA: ESTUDO DE CASO EM UMA POUSADA EM CANOA QUEBRADA - ARACATI/CE

lidade, que consequentemente, será percebida pelo cliente. Dessa forma, todo aperfeiçoamento que é realizado pelos funcionários para se conseguir uma melhoria dos serviços resultarão em melhores condições de competitividade.

O empreendimento hoteleiro que presta um serviço de qualidade aos seus clientes terá um retorno positivo, ou seja, sua empresa vai crescer, por esse motivo, é importante que os funcionários atendam sempre os clientes de forma adequada, pois o cliente busca encontrar um ambiente hospitaleiro. Assim, quando uma empresa dispõe de funcionários que possuem simpatia e atenção no ato do atendimento ao cliente, a empresa crescerá cada vez mais.

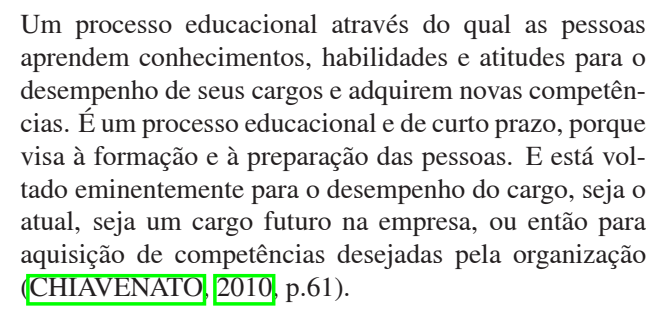

Um processo educacional através do qual as pessoas aprendem conhecimentos, habilidades e atitudes para o desempenho de seus cargos e adquirem novas competências. É um processo educacional e de curto prazo, porque visa à formação e à preparação das pessoas. E está voltado eminentemente para o desempenho do cargo, seja o atual, seja um cargo futuro na empresa, ou então para aquisição de competências desejadas pela organização (CHIAVENATO 2010 p.61).

Para Chiavenato (2010, p.64), o intuito do treinamento é preparar as pessoas para que possam desempenhar bem seus cargos atuais e futuros, podendo transmitir informações, conhecimentos, habilidades e atitudes. Quando o funcionário não é treinado, fica inseguro para exercer sua tarefa com eficiência, produtividade e qualidade. Além disso, se tornará um funcionário lento na execução de suas responsabilidades, podendo errar facilmente, perder tempo e qualidade, fazendo com que o gerente, o cliente, como também o próprio funcionário fique irritado com a situação.

Nesse sentido, Chiavenato fala da importância do treinamento tanto para a empresa, como também para o funcionário, porque irá proporcionar um trabalho excelente, produtivo, com qualidade, presteza, correção e utilização correta do material. Além disso, a gratificação pessoal, por ser bom naquilo que está fazendo Chiavenato (2010, p.64).

As empresas prestadoras de serviço devem apostar fundamentalmente na qualidade do elemento humano, já que a excelência do serviço, condição da competitividade e sobrevivência da empresa, depende de como esse elemento humano está interagindo com os clientes. Essa qualidade se obtém através da educação e do treinamento. Portanto, para as empresas prestadoras de serviço, existe uma estreita correlação entre o nível de educação e treinamento dado aos seus empregados e a sua competitividade e sobrevivência (CASTELLI. 2003 p.29).
Essas empresas prestadoras de serviços para garantirem sua sobrevivência, competitividade e sucesso no mercado, necessitam de pessoas capazes, com excelente qualificação pessoal, que possuem espírito de serviço, capacidade de recuperação e espírito de equipe (CASTELLI, 2003, p.38).

O treinamento é um investimento para a empresa, pois capacita a equipe de trabalho, diminuindo os erros, e assim atingindo os objetivos esperados. Através do treinamento é que se pode atingir níveis de desempenho estabelecidos pelas empresas. Para que o funcionário possa prestar um serviço com qualidade, é preciso capacitá-lo, através de treinamentos específicos para cada área na qual o mesmo atua.

Entende-se, portanto, que os empresários hoteleiros devem apostar na qualificação profissional, através de treinamentos para melhor conhecimento sobre os serviços que serão prestados, onde os funcionários poderão inovar na forma como atendem os clientes da empresa hoteleira.

\subsection{Ações e Atitudes que os Funcionários devem ter para a Excelência no Atendimento aos Cli- entes}

Uma das principais ações que a empresa hoteleira dispõe para garantir a fidelização do cliente, através da qualidade no atendimento, é o comportamento adequado dos funcionários junto aos clientes. E para a melhoria dessa qualidade as empresas hoteleiras necessitam do comprometimento de todos os funcionários, pois não basta que elas busquem melhorias se os profissionais não estão comprometidos.

De acordo com Almeida, (2001, p.65) apud Santos (2010) na prática do atendimento podem-se separar as atitudes em três grandes linhas de ação, conforme Quadro[1]

Diante disso, percebe-se que a atitude ativa é um comportamento obrigatório onde o funcionário deve sempre agir de uma determinada maneira, com ou sem estímulo do cliente. A atitude reativa ao contrário da atitude ativa, só ocorre se houver uma ação do cliente que a justifique. Já atitude pró-ativa é fruto de uma oportunidade detectada pelo funcionário que atende ao cliente, ou seja, é algo que depende da capacidade de enxergar oportunidades de se fazer algo mais.

Segundo Walker (1991, p. 122), apud Barbosa, Trigo e Santana (2015), são dez os mandamentos do bom atendimento:

1. Atenda bem todas as pessoas - supere uma eventual má impressão inicial que o cliente, porventura, tenha causado, sorria. Seja cortês e paciente 


\begin{tabular}{|l|c|l|}
\hline \multirow{3}{*}{ Atendimento ao cliente } & Ativas & \multicolumn{1}{|c|}{$\begin{array}{l}\text { Devem ser praticadas sempre que um servidor esteja atendendo ao } \\
\text { público. }\end{array}$} \\
\cline { 2 - 3 } & Reativas & $\begin{array}{l}\text { Praticadas apenas se acionado pelo cliente. É uma ação deixada pelo } \\
\text { cliente. }\end{array}$ \\
\cline { 2 - 3 } & Pró-ativas & $\begin{array}{l}\text { Põem-se em prática quando houver uma oportunidade, ou for conveni- } \\
\text { ente aplicá-las. }\end{array}$ \\
\hline \multicolumn{2}{|c|}{ Fonte: Almeida (2001, p.65) apud Santos (2010). }
\end{tabular}

utilizando sempre o tratamento "senhor" e "senhora".

2. Atenda de imediato - não deixe o cliente esperando. Aja com rapidez. "Por favor, aguarde que vou atendê-lo (a) em seguida..." é uma maneira de pedir paciência ao cliente. Mas lembre-se: rapidez não é sinônimo de afobação e nervosismo.

3. Dê atenção ao cliente - o cliente mais importante é aquele que está na nossa frente conversando conosco. É essencial que ele perceba isso.

4. Mostre boa vontade - o cliente precisa ver em nós o interesse em satisfazê-lo. Procure entender como ele se sente e como ele gostaria de ser tratado.

5. Preste orientação segura - primeiro é necessário identificar a necessidade do cliente e depois, de maneira segura, dar as devidas orientações. Se você não sabe como orientá-lo, diga isso a ele e vá buscar a solução com alguém que conheça o assunto.

6. Utilize vocabulário do cotidiano - devem ser utilizadas palavras de fácil entendimento sempre evitando as gírias. Evite também usar as siglas internas, que em si não digam nada. Fique certo de que o cliente entendeu suas orientações.

7. Não dê ordens - o cliente não gosta de ser mandado. Em vez de "entre na fila" diga, "por favor, aguarde na fila".

8. Não discuta com o cliente - de que adianta ganhar a discussão e perder o cliente? Não encare as reclamações do cliente como uma crítica pessoal a você. Ouça o cliente irritado sem interrompê-lo. Se assim mesmo ele não se acalmar, encaminhe-o ao gerente do setor competente.

9. Fale a verdade - trate o cliente sempre com honestidade. Mesmo não sendo agradável, é melhor assumir uma eventual falha do que dar ao cliente a impressão de que está escondendo informações ou omitindo problemas.

10. Crie e sugira soluções - busque, com sua equipe, soluções criativas para a melhoria do atendimento. Lembre-se: você é o ouvido da empresa.

Portanto, para se alcançar um bom atendimento, o funcionário deve se comportar de forma correta quando estiver atendendo algum cliente. Além disso, deve-se estar motivado com o ambiente de trabalho, pois a motivação do profissional colabora de forma significativa para a qualidade dos serviços prestados. Assim o ambiente de trabalho torna-se um local acolhedor tanto para os funcionários como também para os hóspedes.

\section{ANÁLISE DOS DADOS COLETADOS NA POUSADA VIA LÁCTEA}

Canoa Quebrada é uma praia localizada no litoral leste do Estado do Ceará, distante $163 \mathrm{~km}$ de Fortaleza e 12 $\mathrm{km}$ da sede do município de Aracati, à qual pertence. E a pousada Via Láctea fica próxima da praia de Canoa Quebrada, o que é um diferencial para os hóspedes, e possui 10 apartamentos, sendo que 6 são duplos, 2 triplos e 2 quádruplos, todos com aconchegante varanda entre o verde dos coqueiros e o azul do oceano que fica na frente. Possui também 6 chalés que são mais amplos, onde 3 são triplos, 1 quádruplo e 2 quíntuplos com vista para o mar e, também ficam próximos à piscina.

De acordo com a pesquisa realizada, verificou-se que dos 25 hóspedes entrevistados, 52\% dos hóspedes avaliam como excelente a Pousada como um todo, $48 \%$ avaliam como ótimo e ninguém respondeu que era bom, regular e ruim (Gráfico 1). O que mostra que a Pousada possui, segundo os entrevistados, qualidade no atendimento dos serviços prestados.

Gráfico 1: Qual a sua percepção da Pousada como um todo.

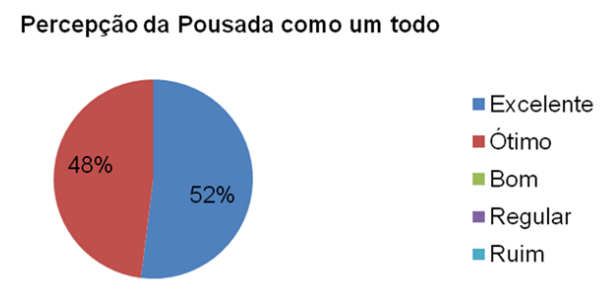

Fonte: Dados coletados, 2016

Quanto ao grau de satisfação com o atendimento da recepção no momento do check-in e check-out, $96 \%$ dos hóspedes se sentem satisfeito, $4 \%$ insatisfeito e nenhum dos entrevistados respondeu parcialmente insa- 
A IMPORTÂNCIA DA EXCELÊNCIA NO ATENDIMENTO COMO DIFERENCIAL COMPETITIVO PARA A EMPRESA HOTELEIRA: ESTUDO DE CASO EM UMA POUSADA EM CANOA QUEBRADA - ARACATI/CE

tisfeito (Gráfico 2). O que demonstra que os hóspedes estão satisfeitos com o atendimento no momento do check-in e check-out.

Gráfico 2: Qual o seu grau de satisfação com o atendimento da recepção em relação ao check-in e check-out.

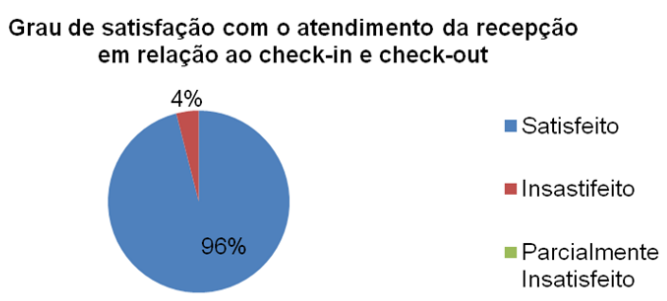

Fonte: Dados coletados, 2016.

Com relação à apresentação dos funcionários, os hóspedes responderam o seguinte: $28 \%$ disseram que a apresentação é excelente, $56 \%$ avaliam como ótimo, $16 \%$ disseram que é bom e ninguém respondeu regular e ruim (Gráfico 3). O que mostra que a apresentação dos funcionários na percepção dos hóspedes está adequada para o ambiente de trabalho, ou seja, estão satisfeitos.

Gráfico 3: Como você avalia a apresentação dos funcionários.

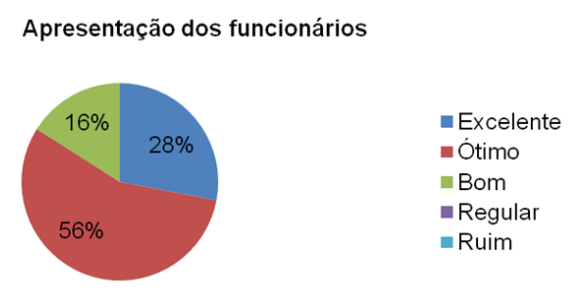

Fonte: Dados coletados, 2016.

Quando perguntados sobre o tratamento dos funcionários da Pousada, 28\% dos hóspedes responderam que o tratamento está excelente, $60 \%$ responderam ótimo, $12 \%$ disseram que é bom e ninguém respondeu regular e ruim (Gráfico 4). Mostrando assim, que o tratamento dos funcionários para com os hóspedes é feita de forma educada, ou seja, está satisfatória para os hóspedes.

Quando questionados sobre a qualidade do setor de Alimentos e Bebidas no que diz respeito ao café da manhã, $44 \%$ dos hóspedes avaliam como excelente, $44 \%$ responderam ótimo, $12 \%$ disseram que era bom e ninguém respondeu regular e ruim (Gráfico 5). O que demonstra que o setor de Alimentos e Bebidas está satisfazendo os hóspedes no café da manhã.
Gráfico 4: Como você avalia o tratamento dos funcionários.

Tratamento dos funcionários

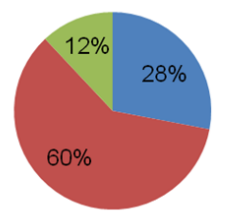

Excelente

átimo

Bom

- Regular

- Ruim

Gráfico 5: Em relação à qualidade do setor de Alimentos e Bebidas no que diz respeito ao café da manhã.

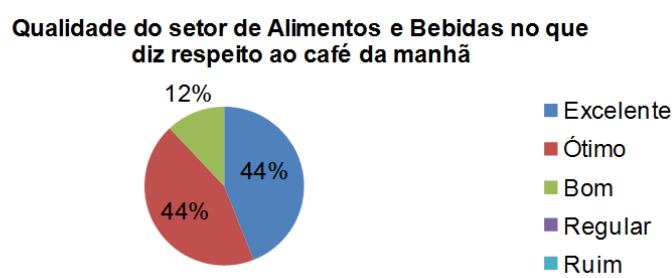

Fonte: Dados coletados, 2016.

Com relação à satisfação dos hóspedes com o serviço do setor de Governança, $86 \%$ está satisfeito, $8 \%$ está insatisfeito e $6 \%$ está parcialmente insatisfeito (Gráfico 6). Isso mostra que o serviço de Governança está satisfazendo os hóspedes, mas precisa melhorar em alguns pontos mencionados pelos entrevistados: a limpeza das Unidades Habitacionais e disponibilização de toalhas de rosto.

Gráfico 6: Ficou satisfeito com serviço do setor de Governança (arrumação dos quartos).

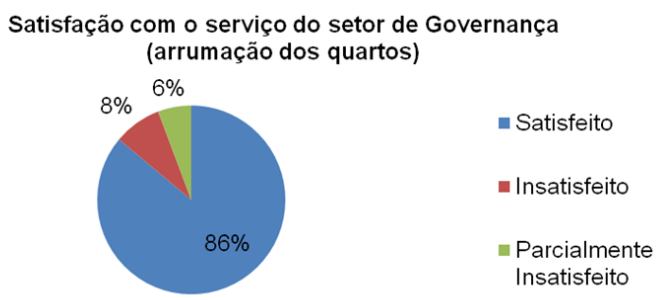

Fonte: Dados coletados, 2016.

Quando perguntados sobre o número de vezes que estiveram na Pousada, 92\% dos hóspedes responderam 
A IMPORTÂNCIA DA EXCELÊNCIA NO ATENDIMENTO COMO DIFERENCIAL COMPETITIVO PARA A EMPRESA HOTELEIRA: ESTUDO DE CASO EM UMA POUSADA EM CANOA QUEBRADA - ARACATI/CE

ter estado 1 a 2 vezes, já $8 \%$ responderam de 3 a 4 vezes (Gráfico 7). O que demonstra que os hóspedes são clientes novos que precisam ser fidelizados.

Gráfico 7: Quantas vezes estiveram na Pousada.

Número de vezes que os hóspedes estiveram na Pousada

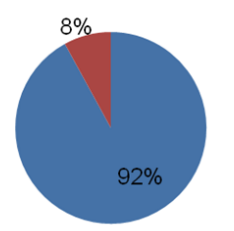

1 à 2

- 3 à 4

5 à 6

- 7 à 8

9 à 10

Acima de 10

Fonte: Dados coletados, 2016.

Em relação ao hóspede ter vivenciado algum problema na Pousada, $12 \%$ responderam que sim e $88 \%$ responderam que não (Gráfico 8). O que demonstra que alguns problemas precisam ser resolvidos como a falta de água quente em algumas Unidades Habitacionais e o desconforto dos colchões. Sendo assim poderá melhorar a satisfação dos hóspedes e posteriormente fidelizálos.

Gráfico 8: Vivenciou algum problema na Pousada.

Vivência de algum problema pelo hóspede na Pousada

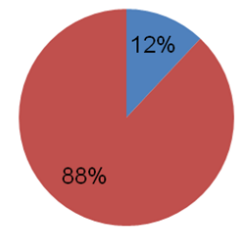

Fonte: Dados coletados, 2016.

Com relação à cordialidade dos funcionários, $100 \%$ dos hóspedes responderam que são cordiais. O que mostra que os clientes estão satisfeitos com o modo como são tratados pelos funcionários da Pousada.

Os hóspedes quando questionados sobre um ponto positivo e negativo com relação ao atendimento, de acordo com sua percepção, a maioria não soube apontar, e os que apontaram falaram somente pontos positivos que foram: receptividade muito boa dos funcionários, variedade no café da manhã, funcionários prestativos e atenciosos e organização dos mesmos no ato do atendimento.
A Pousada pesquisada possui quatro funcionários na área de hospitalidade e não fora oportunizado até então treinamento na área de atendimento para eles pela pousada. Entretanto, de acordo com o relato da Gerência da Pousada, a qualificação dos funcionários é muito importante, porque o funcionário qualificado na sua própria área atenderá o cliente bem e como consequência atrairá mais clientes.

Segundo a Gerência da Pousada, a satisfação do cliente é considerada como um diferencial, pois o que faz a diferença é o atendimento que quando é bom gera satisfação. Ela considera também a qualidade no atendimento um fator de sobrevivência para qualquer empreendimento e se o lugar possuir essa qualidade logo terá clientes fiéis, pois o cliente gosta de serviços de qualidade e busca ser bem tratado, então o atendimento precisa ser diferenciado. Além disso, de acordo com a Gerência, a apresentação e o tratamento dos funcionários são fundamentais para a permanência do cliente, pois já dizem que a primeira impressão é a que fica e quando o funcionário atende bem o cliente, o mesmo sairá satisfeito e ainda ajudará no marketing do empreendimento, melhorando as condições de competitividade.

\section{CONSIDERAÇÕES FINAIS}

Com a realização desse artigo pôde-se perceber que o grau de satisfação dos hóspedes da Pousada Via Láctea é satisfatório.

No início do trabalho, através de pesquisas bibliográficas, foi possível conhecer vários conceitos sobre qualidade que são abordados por vários autores. Depois, foi realizada a pesquisa de campo na Pousada, onde foram aplicados questionários aos hóspedes e uma entrevista com a Gerência da Pousada, o que possibilitou a coleta de informações, permitindo a chegada da resolução do problema da pesquisa e a comprovação da hipótese definida inicialmente. Além disso, foi possível mostrar as vantagens que se tem através da qualidade dos serviços prestados, identificando alguns pontos positivos da Pousada e pontos que a empresa precisa melhorar para satisfazer os hóspedes.

O resultado da análise dos dados coletados mostra que a Pousada Via Láctea possui qualidade nos serviços prestados, o que torna um diferencial competitivo frente aos outros empreendimentos hoteleiros.

Foram avaliados durante a pesquisa e através do atingimento dos objetivos específicos, como os hóspedes são tratados pelos funcionários e quais os pontos negativos e positivos quanto à qualidade dos serviços de acordo com a percepção dos clientes. E também, quais as ações que melhorariam a qualidade dos servi- 
A IMPORTÂNCIA DA EXCELÊNCIA NO ATENDIMENTO COMO DIFERENCIAL COMPETITIVO PARA A EMPRESA HOTELEIRA: ESTUDO DE CASO EM UMA POUSADA EM CANOA QUEBRADA - ARACATI/CE

ços aos clientes e as principais dificuldades em manter a qualidade dos serviços.

Foi considerado diante dos objetivos do estudo, que a hipótese foi confirmada e acredita-se que a inovação na qualificação profissional dos funcionários é um fator importante para garantir uma excelente qualidade dos serviços e, consequentemente, a fidelização dos clientes. Apesar do resultado da pesquisa ter sido satisfatório, existem pontos negativos que precisam ser melhorados e que foram observados pelos hóspedes nas Unidades Habitacionais da Pousada, e que estão relacionados à arrumação dos quartos (melhorar a limpeza dos móveis), manutenção dos chuveiros elétricos e desconforto dos colchões. E, além disso, constatou-se que os hóspedes são clientes novos que precisam ser fidelizados, o que reforça a hipótese de que a qualificação dos funcionários é de extrema importância para garantir uma excelente qualidade dos serviços e posteriormente fidelizar o hóspede.

Após a melhoria dos pontos negativos e a inovação na qualificação dos funcionários da Pousada de acordo com a área em que atuam, ou seja, se aperfeiçoar mais no que fazem, pode-se ter uma qualidade dos serviços excelente que irá satisfazer os hóspedes e superar suas expectativas, pois a qualificação deixa o funcionário mais comprometido com o trabalho, fazendo com que a Pousada tenha uma vantagem competitiva no mercado da hotelaria, e com isso possa alcançar a fidelidade dos hóspedes.

Portanto, percebe-se que a qualidade dos serviços prestados é muito importante para qualquer meio de hospedagem, pois quando o cliente procura algum lugar onde possa se hospedar, espera ser bem tratado, de modo que, os serviços hospitaleiros venham de encontro as suas necessidades. Além disso, é um fator primordial para uma empresa hoteleira, pois faz com que o cliente se sinta satisfeito e retorne outras vezes e ainda poderá ajudar no marketing do empreendimento hoteleiro de forma positiva.

\section{REFERÊNCIAS}

BARBOSA, T.; TRIGO, A.; SANTANA, L. Qualidade no atendimento como fator de crescimento empresarial. 2015. Disponível em: <http://www.cairu.br/riccairu/pdf/artigos/2/08_ QUALIDADE_ATENDIMENTO_FATOR.pdf $>$. Acesso em: 24 de junho de 201.

BOND, M. T.; BUSSE, A.; PUSTILNICK, R. Qualidade total: o que é e como alcançar. Curitiba: Intersaberes, 2012.
BULGACOV, S. Manual de gestão empresarial. 2. ed. São Paulo: Atlas, 2006.

CAStelli, G. Administração Hoteleira. 9. ed. Caxias do Sul: EDUCS, 2003.

CHIAVENATO, I. Iniciação à administração de recursos humanos. 4. ed. Barueri: Manole, 2010.

CORRÊA, H. L.; CAON, M. Gestão de serviços: lucratividade por meio de operações e de satisfação dos clientes. 1. ed. São Paulo: Atlas, 2006.

CUSTODIO, M. F. Gestão da qualidade e produtividade. São Paulo: Pearson Education do Brasil, 2015.

DIAS, R.; PIMENTA, M. A. Gestão de hotelaria e turismo. São Paulo: Pearson Prentice Hall, 2005.

GOZZI, M. P. Gestão da qualidade em bens e serviços - GQBS. São Paulo: Pearson Education do Brasil, 2015.

PETROCCHI, M. Hotelaria: planejamento e gestão. São Paulo: Pearson Prentice, 2007.

SANTOS, M. F. Melhoria da Qualidade do atendimento. 2010. Disponível em: <http: //www.academia.edu/3007701/Melhoria_da Qualidade_do_Atendimento> Acesso em: 24 de maio de 2016. 